\title{
Reduction of Free Water Clearance by Chlorpropamide
}

\author{
A. G. HOCKEN,* M.B., M.R.C.P., M.R.C.P.ED. ; D. LONGSON, † M.B., F.R.C.P.
}

Brit. med. F., 1968, 1, 355-356

The only effective method of treating diabetes insipidus is by the administration of antidiuretic hormone, but all the currently available preparations have recognized shortcomings.

Vasopressin tannate in oil by intramuscular injection is painful, and in preparing the injection considerable care is required to ensure its effectiveness. The nasal insufflation of snuff of ten causes rhinitis, leading to a loss of efficacy. The more recently available synthetic preparation, while more acceptable to the patient, has a limited duration of action. Finally, antibodies to exogenous vasopressin have recently been described (Pepys et al., 1966).

Any treatment which decreases the need for substitution therapy is worthy of consideration. Thiazide diuretics have been advocated (Crawford and Kennedy, 1959), particularly for nephrogenic diabetes insipidus, though they will also exert a paradoxical antidiuretic effect in antidiuretic-hormone-sensitive forms of the disease. Their mode of action has been investigated (Baba et al., 1965 ; Havard, 1965), but is not fully understood. However, a decrease in free water clearance may apparently be induced by all types of natriuretic agents, except those acting on the basis of aldosterone antagonism (Lant et al., 1967).

The recent observations that metformin, chlorpropamide, and paracetamol (acetaminophen) exert a useful antidiuretic activity are of interest (Katsuki and Ito, 1966 ; Arduino et al., 1966 ; Nusynowitz and Forsham, 1966). The present communication describes an investigation of the claims for chlorpropamide, both in cases of established diabetes insipidus and in healthy controls.

\section{Patients and Methods}

Four patients were studied, including a girl of 9 years suffering from nephrogenic diabetes insipidus. The other three patients had antidiuretic-hormone-sensitive disease-a 40-yearold woman had a small chromophobe adenoma and two men had diabetes insipidus of unknown origin. Three normal healthy subjects were also examined.

All patients were admitted to hospital after withdrawal of vasopressin therapy and given standard ward diet. After deprivation of fluid from midnight, the investigations were undertaken from 8 a.m. to 12 midday. The control subjects were given a water load of 1 litre some time between 7.30 and 8.30 a.m. to ensure maximum diuresis. Thereafter accurately timed urine voidings were made, usually at one-hour intervals, over a four-hour period. Water equal in volume to the urine passed was given on each occasion to maintain the diuresis.

Chlorpropamide, $250 \mathrm{mg}$. or later $500 \mathrm{mg}$. (with the exception of the child, who received $100 \mathrm{mg}$.) was given each morning, except on control days. The usual pattern was two days of control observations, followed by three days of drug treatment. Lengthier trials were undertaken in control persons and in one patient who underwent a single blind trial.

Each specimen of urine was measured and analysed for osmolality (by freezing-point depression) and creatinine concentration (autoanalyser). At least one serum sample from each period of investigation was also analysed for creatinine and osmolality.

- Registrar. t Consultant Physician. Department of Endocrinology, the Royal Infirmary, Manchester 13.

\section{Results}

In three patients and two controls there were no effects of chlorpropamide on any of the renal functions measuredcreatinine, osmolar, and free water clearance $\left(\right.$ C. $_{\mathrm{H}_{2} \mathrm{O}}$ ) $\longrightarrow$ or on the plasma osmolality.

In one patient, a 30-year-old man, there was a marked fall of free water clearance and of serum osmolality after the administration of chlorpropamide (Fig. 1).

One control subject, a 34-year-old man, showed significant free water retention (Fig. 2) in response to chlorpropamide in the doses indicated.

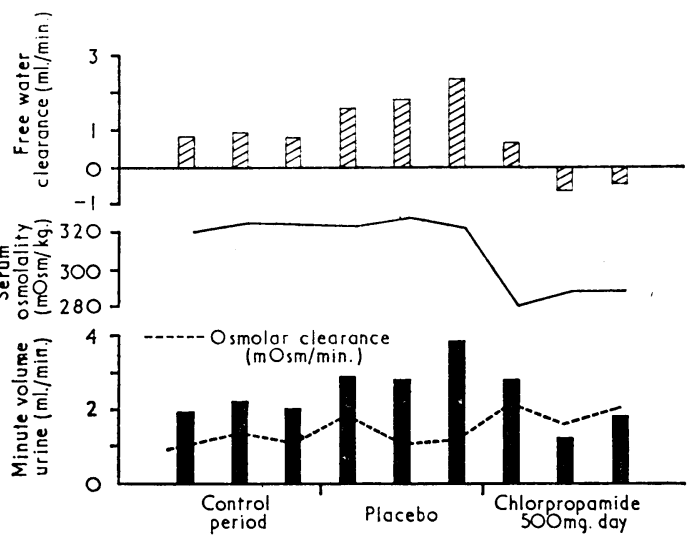

FIG. 1.-Effect of chlorpropamide $500 \mathrm{mg}$. daily on free water clearance in subject with diabetes insipidus. Note the fall of serum osmolality to physiological levels during treatment with chlorpropamide.
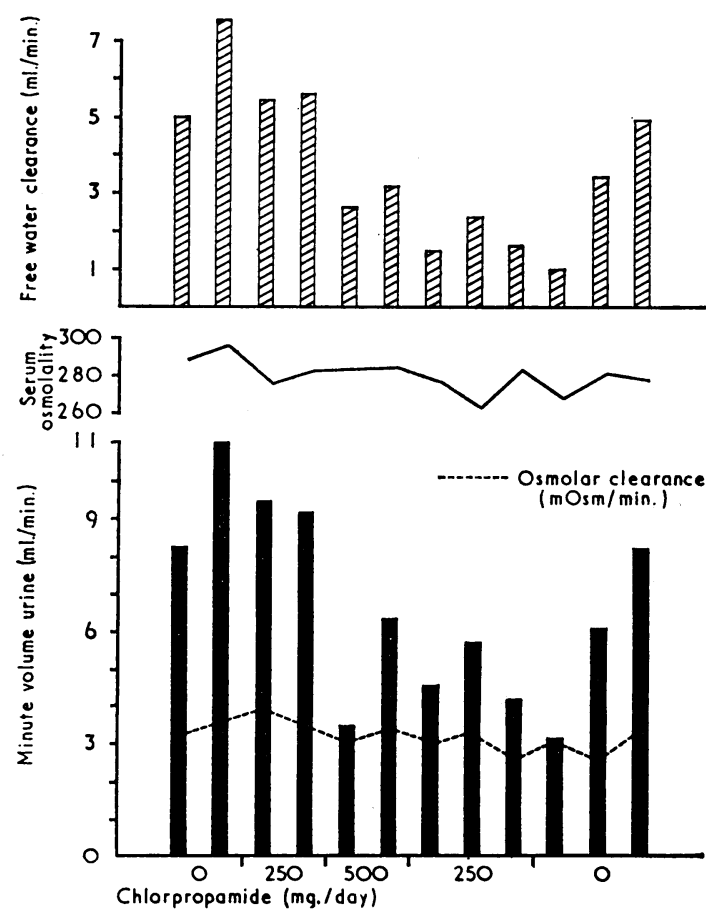

FIG. 2.-Effect of chlorpropamide $500 \mathrm{mg}$. daily on free water clearance of healthy control. 


\section{Discussion}

There can be little doubt of the efficacy of chlorpropamide in reducing free water clearance in two of these seven subjects. The mean value for each measurement for the whole of each experimental day is shown in the figures. Note that negative free water clearance was attained by both the patient (Fig. 1) and the control subject during some one-hour periods while taking chlorpropamide. Published experience seems to indicate that the effect is not predictable from patient to patient, though it is so in a given patient. Meinders et al. (1967) found a uniform effect in all patients, though they did not report any patient with nephrogenic disease. In the latter case Arduino et al. (1966) found their only failure. However, Katsuki and Ito (1966) noted a spectrum of success as measured by a " percentage reduction of urine volume." While reduction of urine volume may reflect diminution of free water clearance, this is not necessarily clearly so. It is probably better to specifically measure $\mathrm{C}_{\mathrm{H}_{2} \mathrm{O}}$.

One might wonder what part the dietary modifications had in contributing to the antidiuresis in the patients of Meinders et al. (1967) in view of attempts to reduce osmolar load as a method of treatment (Mudge, 1958), but it seems unlikely to be relevant in view of the dietary freedom in the outpatient studies. In contrast to our observations, they did not encounter an antidiuresis in control subjects. It is probable that their experiments were not conducted under maximum water diuresis, since urine osmolality fell only to $200 \mathrm{mOsm}$.

The most striking point in the evaluation of our patient was the restoration to normal levels of the plasma osmolality during the period of chlorpropamide treatment, falling from the pathological level of greater than 320 to $285-290 \mathrm{mOsm}$./1. (Barlow and de Wardener, 1959). One would not expect significant alteration of the plasma osmolality of a normal adult under a 1 litre load of water, since the latter represented no more than $2 \%$ of total body water as measured by the method of using tritiated water (Veall and Vetter, 1958).

In connexion with this therapy two anecdotes are worth relating. Our patient, while receiving his loading dose of chlorpropamide as an outpatient, was afflicted by gastrointestinal and subjective disturbances, clearly attributable to the disulfiram-like effect which chlorpropamide may produce (Meyler, 1963). For three days he had needed no vasopressin by his own standards, quite unprecedented since the diagnosis of his disease 18 months previously. Attributing his disability to lack of vasopressin he took a single dose by inhalation 48 hours before being admitted for investigation. During that time also not only was no vasopressin called for, but, having no access to alcohol, he remained well.

For more than 20 years a 54 -year-old woman had been in the habit of taking a quart $(1,140 \mathrm{ml}$.) of drinking-water to bed with her. Three years before she came to our attention diabetes mellitus had been diagnosed. The polyuria and polydipsia was attributed to glycosuria and an element of hysterical polydipsia. However, having begun treatment with chlorpropamide, of which $100 \mathrm{mg}$. daily now controls her diabetes mellitus, the patient's entirely spontaneous observation on the relief of her insatiable thirst was striking (G. M. Berlyne, personal communication).
The mechanism of action is at the moment quite obscure. Katsuki and Ito (1966) clearly showed the prolongation of the normal effective period of vasopressin. From our studies, hypoglycaemia per se does not seem to be an influential factor, since insulin treatment of the susceptible control produced no reduction of $\mathrm{C}_{\mathrm{H}_{2} \mathrm{O}}$. Furthermore, hypoglycaemic symptoms at blood sugar levels of $50 \mathrm{mg} . / 100 \mathrm{ml}$. occurred in a refractory control. Variability of pathways of metabolism might be considered in view of the association of the responding patient being victimized by the disulfiram effect, but attempts to produce such an effect in the susceptible control subject failed.

The onset of effect appears to be cumulative according to the data shown in Fig. 2 of Meinders et al. (1967). This is supported by our control study, in so far as $250 \mathrm{mg}$. daily initiated little response, while that to $500 \mathrm{mg}$. daily could not be doubted. Subsequently the response was maintained by $250 \mathrm{mg}$. daily. The offset of effect was also slow (Fig. 2). This pattern is reminiscent of that which one sees in the therapeutic effect of chlorpropamide in the treatment of diabetes mellitus.

Our experience suggests that chlorpropamide may exert a useful therapeutic effect in some cases of diabetes insipidus. There is no available information on which to base selection of patients for such treatment. Though hypoglycaemia has not been reported during the use of chlorpropamide for diabetes insipidus, the possibility of this complication must be borne in mind.

\section{Summary}

The effect of chlorpropamide on free water clearance, creatinine clearance, and osmolar clearance was investigated in four patients with diabetes insipidus and three normal controls. Reduction of free water clearance in one subject of each group was the only value affected by up to $500 \mathrm{mg}$. of chlorpropamide daily.

Our thanks are due to Dr. F. J. A. Bateman and Pfizer Limited, by whose courtesy we had supplies of chlorpropamide and suitable placebo preparations for this investigation.

\section{REFERENCES}

Arduino, F., Ferraz, F. P. J., and Rodrigues, J. (1966). F. clin. Endocr., 26, 1325.

Baba, W. I., Lant, A. F., and Wilson, G. M. (1965). Proc. roy. Soc. Med., 58, 911 .

Barlow, E. D., and de Wardener, H. E. (1959). Quart. F. Med., 28, 235. Crawford, J. D., and Kennedy, G. C. (1959). Nature (Lond.), 183, 891. Havard, C. W. H. (1965). Proc. roy. Soc. Med., 58, 1005.

Katsuki, S., and Ito, M. (1966). Lancet, 2, 530.

Lant, A. F., Baba, W. I., and Wilson, G. M. (1967). Clin. Sci., 33, 11. Meinders, A. E., Touber, J. L., and de Vries, L. A. (1967). Lancet, 2, 544.

Meyler, L. (editor) (1963). Side Effects of Drugs, 4th ed., p. 255. Amsterdam.

Mudge, G. H. (1958). Amer. F. Med., 24, 785.

Nusynowitz, M. L., and Forsham, P. H. (1966). Amer. F. med. Sci., 252, 429.

Pepys, J., Jenkins, P. A., Lachmann, P. J., and Mahon, W. E. (1966). Clin. exp. Immunol., 1, 377.

Veall, N., and Vetter, H. (1958). Radioisotope Techniques in Clinical Research and Diagnosis, p. 194. London. 